\title{
Concept Selection - Applying Pugh Matrices in the Subsea Processing Domain
}

\author{
Linda Lønmo \\ FMC Technologies \& \\ Buskerud University College \\ linda.lonmo@fmcti.com
}

\author{
Gerrit Muller \\ Buskerud University College \\ Gerrit.muller@hibu.no
}

Copyright @ 2014 by Linda Lønmo.

\begin{abstract}
This paper discusses the application of Pugh matrices in concept selections within the subsea processing department of FMC Technologies. The focus is not the concepts themselves or requirements management, but on applying Pugh matrices in conceptual system studies. Previous research by Master students in the oil \& gas industry shows resistance amongst engineers and managers towards using Pugh matrices.

The application of the Pugh matrix in these studies showed that if applied on the correct level of detail as part of the concept selection process, it is a powerful tool. It forces reasoning to be based on explicit criteria and also serves the purpose of documenting the decision making. This level of documentation and definition/selection of criteria goes beyond the normal practice today. The study teams gained a broader and deeper understanding of the design problems in addition to securing the quality of the concept selection process. The involved engineers readily adopted the Pugh matrix and they intend to continue using it, mainly due to its ability to force structural thinking in complex systems.
\end{abstract}

\section{Introduction}

FMC Technologies is the world's leading provider of subsea solutions for the oil \& gas industry. FMC Technologies is a global company with approximately 16,800 employees and operates 30 production facilities in 16 countries. FMC's subsea history dates back to 1967 when FMC Technologies sold and delivered its first subsea tree for use in 20 meters water depth in the Gulf of Mexico. The core business of FMC is still subsea production systems comprising subsea trees and manifolds connected by piping connectors and operated via control systems. Subsea processing is different from traditional production because it involves active treatment of hydrocarbons; separating, cooling and pumping fluids, whilst gas is compressed. While subsea production systems are considered mature technology, subsea processing is still relatively young. Subsea processing systems are solutions to enhance field economics by maximizing recovery, increasing production, and reducing operating costs.

The Tordis Subsea Separation Boosting and Injection (SSBI) system operated by Statoil (Figure 1) was the world's first commercial subsea processing system and delivered by FMC (installed 2007). Subsea separation along with other upgrades to the field infrastructure is expected to increase the recovery factor for the field from 49 to $55 \%$ (approximately 35 million barrels). Tordis is recognized by the industry as one of the most important

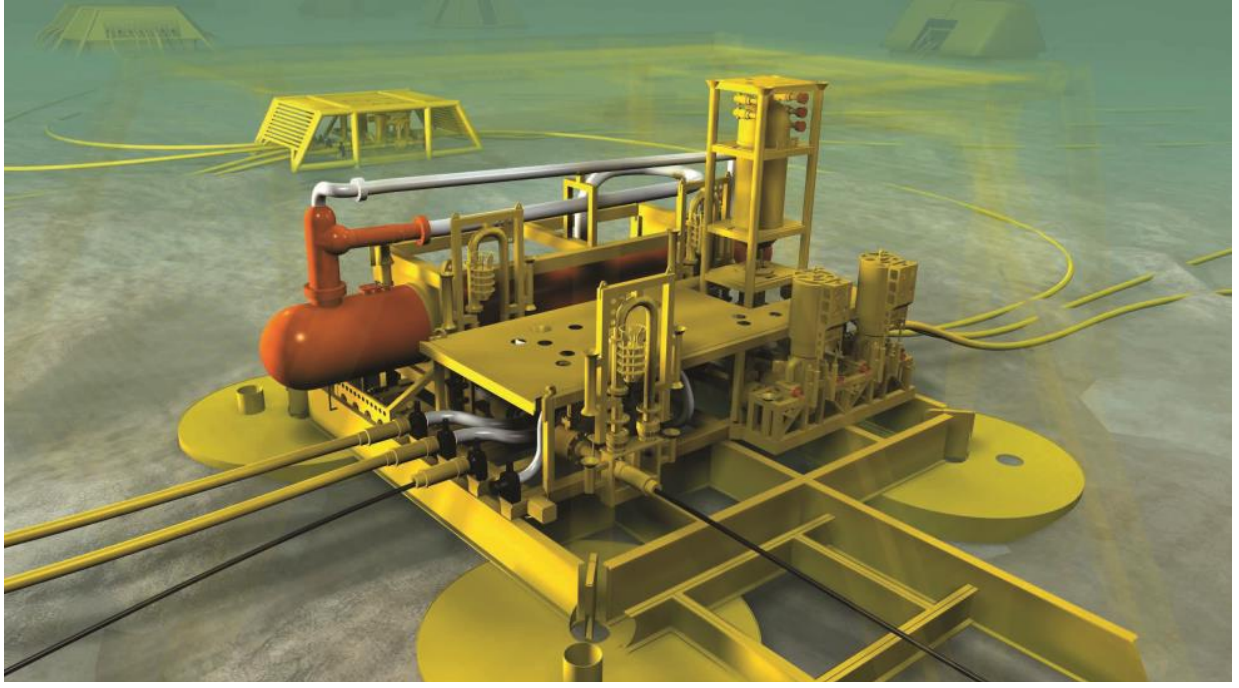

Figure 1: Tordis Subsea System technology milestones for subsea in recent years. Pazflor operated by Total is another of FMC's milestone projects as the first subsea processing system in West Africa offshore Angola. FMC's processing department in Asker executed the Tordis and Pazflor projects. Other than these EPC projects this department works mainly with concept screening studies - Tordis was on the drawing board 10 years before EPC contract award.

Pugh matrices can improve the quality of the concept selection process and facilitate a structured concept selection process. The entry level of the Pugh matrix is relatively low and no specific software is 
required. This paper describes the application and validation of the Pugh matrix for three system studies performed in the subsea process systems department.

\section{Problem Statement}

The goal of the study phase is objective and structured evaluations between alternative system solutions. Short durations, limited budgets, and lack of resources often characterize this phase. These constraints often make engineers rush into the first feasible solution, bypassing systems engineering techniques and processes, in order to finish the work within the allotted time and budget. In addition, customer involvement is often limited during execution of the study making alignment of expectations difficult. Engineers often select concepts based on their experiences and preferences instead of objective and structured evaluations between the alternative solutions. Previous master students have concluded that it is hard to convince experienced (older) engineers to value Concept Selection and evaluation matrices [5,6,7,8].

Concept selections are often in the form of informal meetings with drawings/models as the only documentation. Team members seldom prepare decision logs or minutes of meeting. Many concepts have a number of interrelated parameters, and the human mind struggles to handle the complexity. Concept selections without a proper methodology have a high risk of being inconsistent and unjustified. There is a high risk that the concept chosen is not the best one, and may require redesign later. Redesign in later project phases is expensive and inefficient. Team members seldom prepare decision logs or minutes of meeting. When design decisions are revisited in subsequent phases of the project, or by engineers in similar projects, it is hard to find the reasoning behind the choices. The subsea process systems department needs an improved concept selection process.

\section{Overview of the Pugh Matrix}

Stuart Pugh introduced an evaluation matrix in 1991. This section is based on his book Total Design Integrated Methods for Successful Product Engineering [0]. This matrix is also known as the Pugh matrix. Pugh claimed that matrices in general are the best way of structuring and representing an evaluation, as they add structure and control to the concept selection process. The Pugh matrix facilitates evaluation of alternative solutions against significant criteria. The purpose is to identify the concept that best satisfy the criteria.

\begin{tabular}{ccccc}
\hline Criteria & Concept 1 & Concept 2 & Concept 3 & Concept 4 \\
\hline A & + & - & + & - \\
B & + & S & + & S \\
C & - & + & - & - \\
D & - & + & + & - \\
E & + & - & + & - \\
F & - & - & S & + \\
$\Sigma+$ & 3 & 2 & 4 & 1 \\
$\Sigma-$ & 3 & 3 & 1 & 4 \\
$\Sigma$ S & 0 & 1 & 1 & 1 \\
\hline
\end{tabular}

Figure 2: Standard Pugh Matrix

The Pugh Matrix is not intended to be a mathematical matrix; it is simply a format for expressing ideas and the criteria for the evaluation of these ideas in a visible, userfriendly fashion. The method utilizes one leg of the matrix to express the criteria on the vertical axis. The horizontal axis is used for visualizing the alternative concepts (Figure 2). + (plus): meaning better than, (minus): meaning worse than, and $\mathrm{S}$ meaning same as a defined reference concept. Each criterion is scored for all the cases at the same time. Once the matrix has been fully populated a summary at the bottom shows the individual concept's ability to match the requirements as well as the strengths and weaknesses in the concepts. Pugh highlights that it is impossible to evolve and evaluate all possible solutions to a particular problem, and in order to minimize the possibility of the wrong choice of concept, it becomes essential to carry out concept formulation and evaluation in a disciplined approach. The method is iterative and the matrix is reviewed in cycles until the preferred concept is confirmed and approved by the team members.

Pugh claims that key outputs of concept selections by using the evaluation matrix are:

- a greater insight into the requirements

- a greater understanding of the design problem

- a greater understanding of the potential solutions

- an understanding of the interaction between the proposed solutions, which can give rise to additional solutions

- a knowledge of the reasons why one concept is stronger or weaker than another

- a natural stimulus to produce other concepts.

The method of using the Pugh matrix also makes it difficult for people to push their own ideas for irrational 
reasons or to deliberately attempt to eliminate the bad features of some less acceptable concepts.

\section{Research Methodology}

Several methods were combined in this research (Error! Reference source not found.). Focus was on interaction with members of the different project teams performing the studies and applying the Pugh matrix. The research was performed mainly amongst young engineers, only 2 of the 13 engineers that participated in

the survey, were over 40 years.

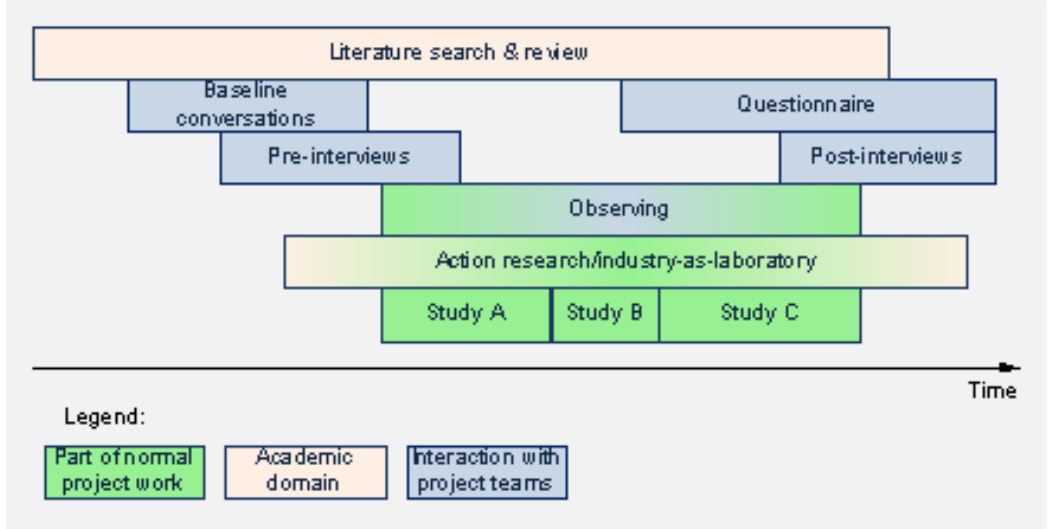

Figure 3: Research Methodology Overview

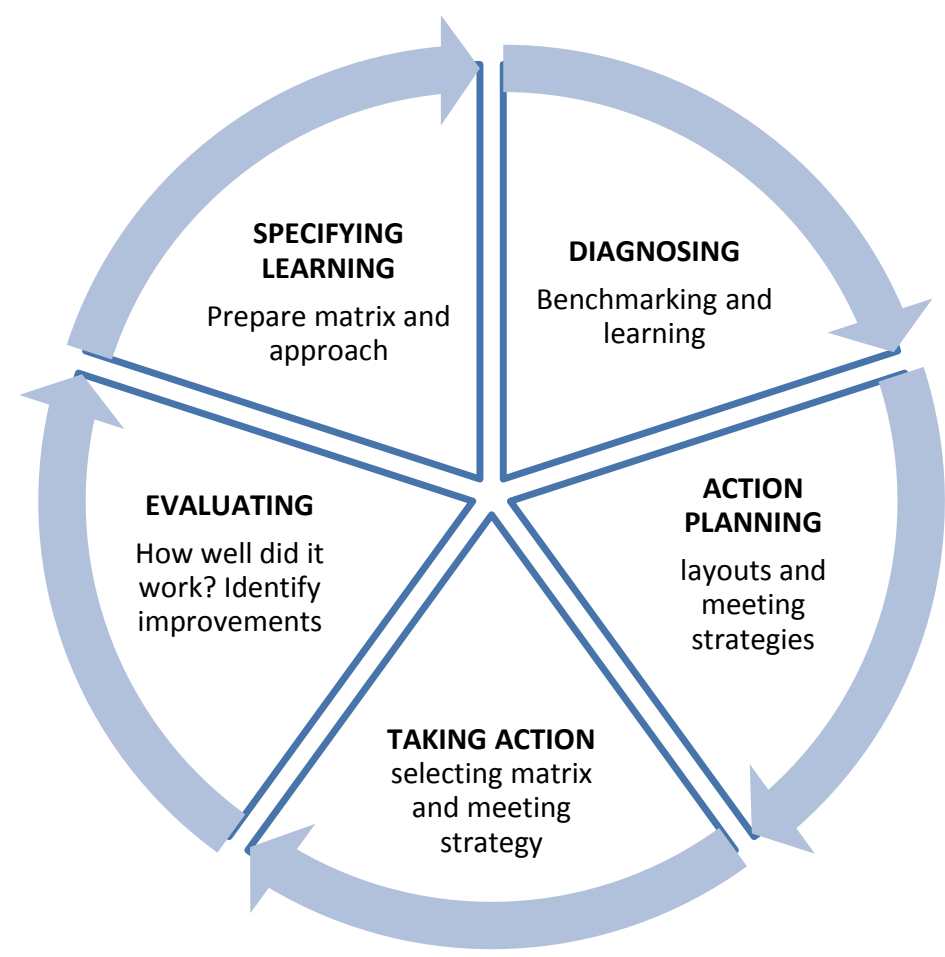

Figure 4: Action Research Cycle
Action research/industry-as-laboratory.

FMC process system studies are multidisciplinary; research of such subjects is complicated by nature as Muller and Heemels discuss in [2]. The "action research/industry-as-laboratory approach" uses the actual industrial setting as a test environment [2, 3]. What separates action research from general professional practices, consulting, or daily problem-solving is the emphasis on scientific study. As part of this paper, the researcher studied the concept selections and investigated the Pugh matrix methodology. Much of the researcher's time was spent on refining the Pugh matrix to suit the situation, and on collecting, analyzing, and presenting data on an ongoing, cyclical basis $[2,3,4]$. Three cycles involving planning, acting, observing and reflecting were performed as part of the research for this paper. Each cycle involved a separate, subsequent system study performed in the subsea process systems department ( 


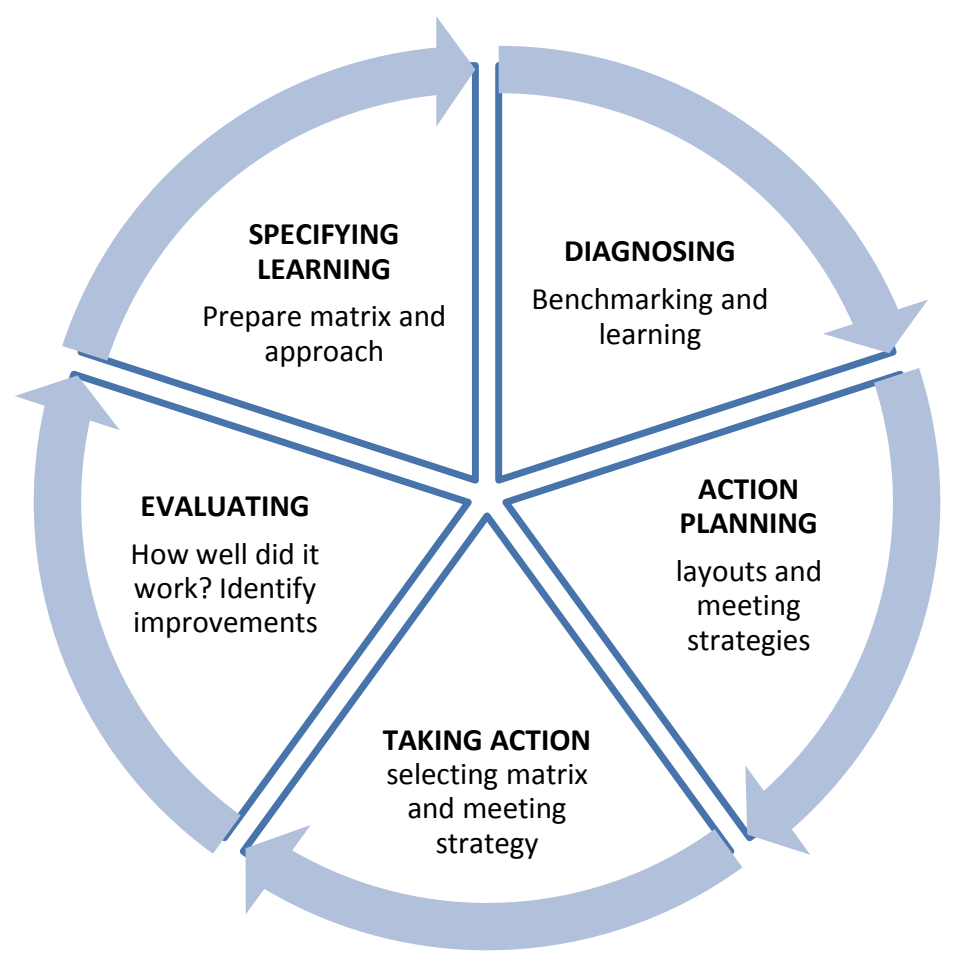

Figure 4).

The researcher informed the study participants of the benefits of the Pugh matrix. This was followed by identification of possible matrix layouts, from which one was implemented. Data on the results of the application of the Pugh matrix was collected and evaluated. The findings were interpreted in light of how successful the concept selection and Pugh matrix were. At this point, the matrix was reassessed and the process begun another cycle [3]. The focus of this paper is not the concepts themselves but on the application of Pugh matrices.

Baseline. The researcher performed door to door conversations to gain information from colleagues in addition to own experience. This also served the purpose of pre-survey prior to the interviews and questionnaire (Error! Reference source not found.). The conversations targeted how concept selections are made today and captured how customer involvement and expectations were normally met.

Interviews. In addition to the baseline conversations, informal interviews were conducted prior to using the Pugh matrix and building the questionnaire. A second series of interviews was performed after concept selection for each study prior to or in parallel with the questionnaire.

Questionnaire. The engineers provided feedback by filling in a questionnaire. The questionnaire had in total 19 questions and took approximately 15 minutes to complete. 12 out of 13 people responded. The questionnaire was formulated after the initial interviews and baselining. It partly overlapped the action research and was distributed to participants immediately after the concept screening.

Observing. The researcher observed the project team during internal concept screening and in meetings with the customer. The researcher noted down meeting progress, atmosphere, type of dialogue, if the meeting stayed on topic, and degree of involvement. The researcher appointed another observer as well.

\section{Subsea Processing System Studies}


The research presented in this paper is based on three system studies performed by the subsea process systems department in Asker. These studies are performed on assignments from the oil companies. The subsea domain is project oriented and the work is characterized by time and cost constraints. The customer outlines a study, and the scope of work is agreed prior to the FMC study team executing the study (Figure 5). When defining the

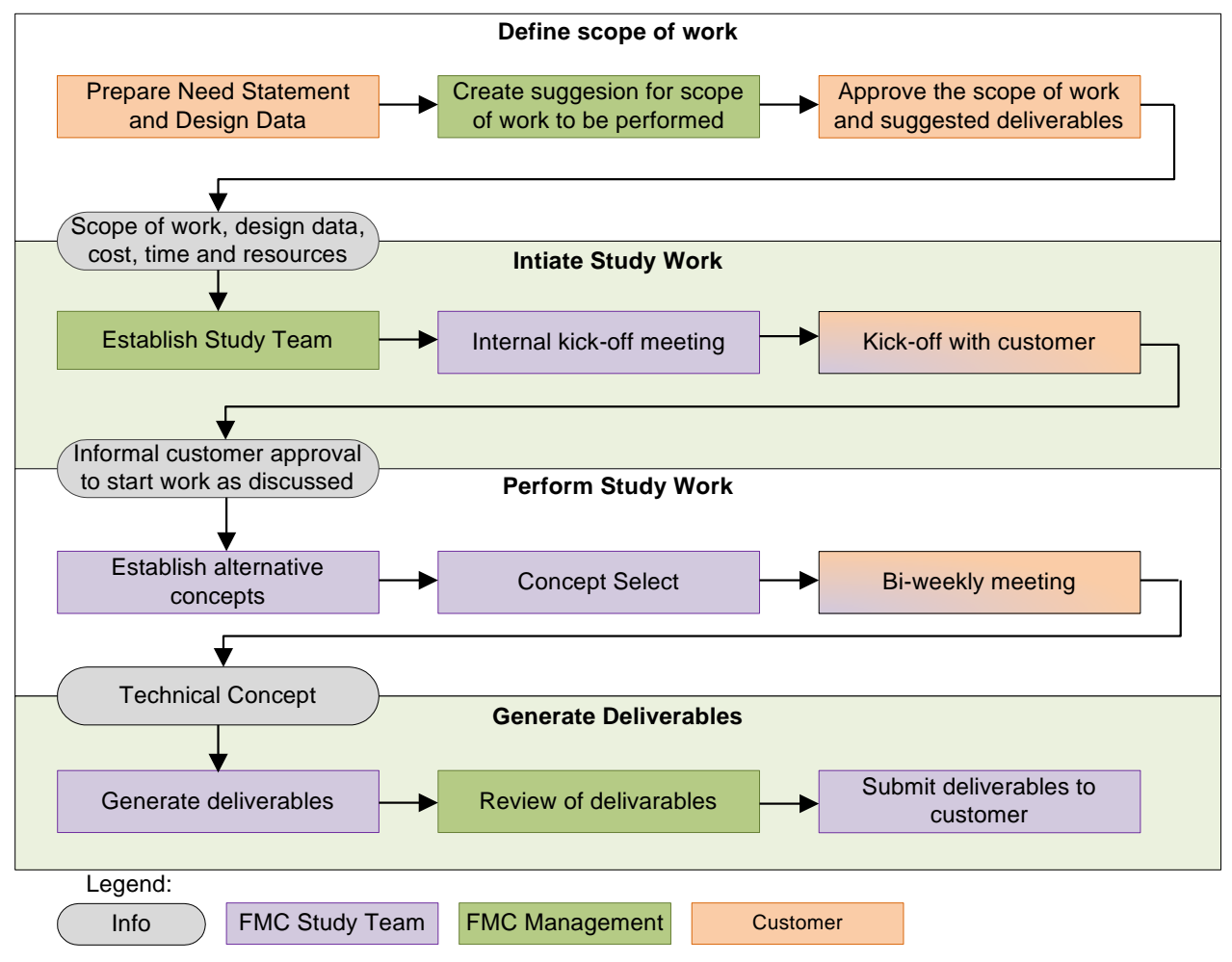

Figure 5: Study Process Overview scope of work and the deliverables, the interaction with the customer is typically from the chief engineer, sales manager, and line managers. At this point, the FMC study team has not been assigned yet. The customers often have their project team involved at this stage. Initiating the study work, the FMC study team arranges internal and external kick-offs and agrees with the customer on how to commence the work. The FMC study teams usually consist of 3 to 6 people and meet bi-weekly with the customer. Duration of the studies normally vary from 2 to 4 months. At the beginning of the study work, the team simulates the system by functional building blocks e.g. liquid pump, gas/liquid separator etc. The functional building blocks are owned by specialist product group departments. After establishing required performance for each function, the product groups are involved to select the appropriate hardware and to identify required development of equipment for alternative concepts. A concept selection is performed (see next section for more details.) FMC managers review the study report and deliverables before submittal to the customer.

When the managers agree on the work to be performed, the pre-screening of potential technical solution typically starts and this is often reflected in the agreed scope of work. This can provide a good starting point, but sometimes it constrains the project team - if assumptions were wrong. The customer provides the reservoir and subsea environment characteristics along with major infrastructure interfaces. FMC specifies requirements and assumption in a separate basis of design document (part of the deliverables).

\section{Baseline of Current Concept Selection Method}

FMC's business management system includes a process for executing studies (Error! Reference source not found.). According to the business process, a concept review (including concept selection) meeting shall be conducted. The current concept selections are mainly organized as working meetings after a pre-screening of potential design solutions have been performed. The meeting responsible prepares a PowerPoint presentation with high-level process flow diagrams (sketches) and an initial bullet list of pros and cons for each alternative. Usually the study team identifies three to four concepts that are explored. The discussion on which case to select progresses while people take notes and a preferred case is agreed. The preferred concept is followed in subsequent phases of the work. The unaltered PowerPoint presentation and people's notes are often the only documentation from the meeting. The dialogues in these meetings are often subjective and unstructured. People advocate their own experiences and preferences. The meetings are often characterized by frequent interruptions by participants, heated discussions, and unstructured change of topics. The atmosphere in these meeting does not always invite all participants to generate ideas or to articulate concerns, especially towards authoritative figures and managers. 


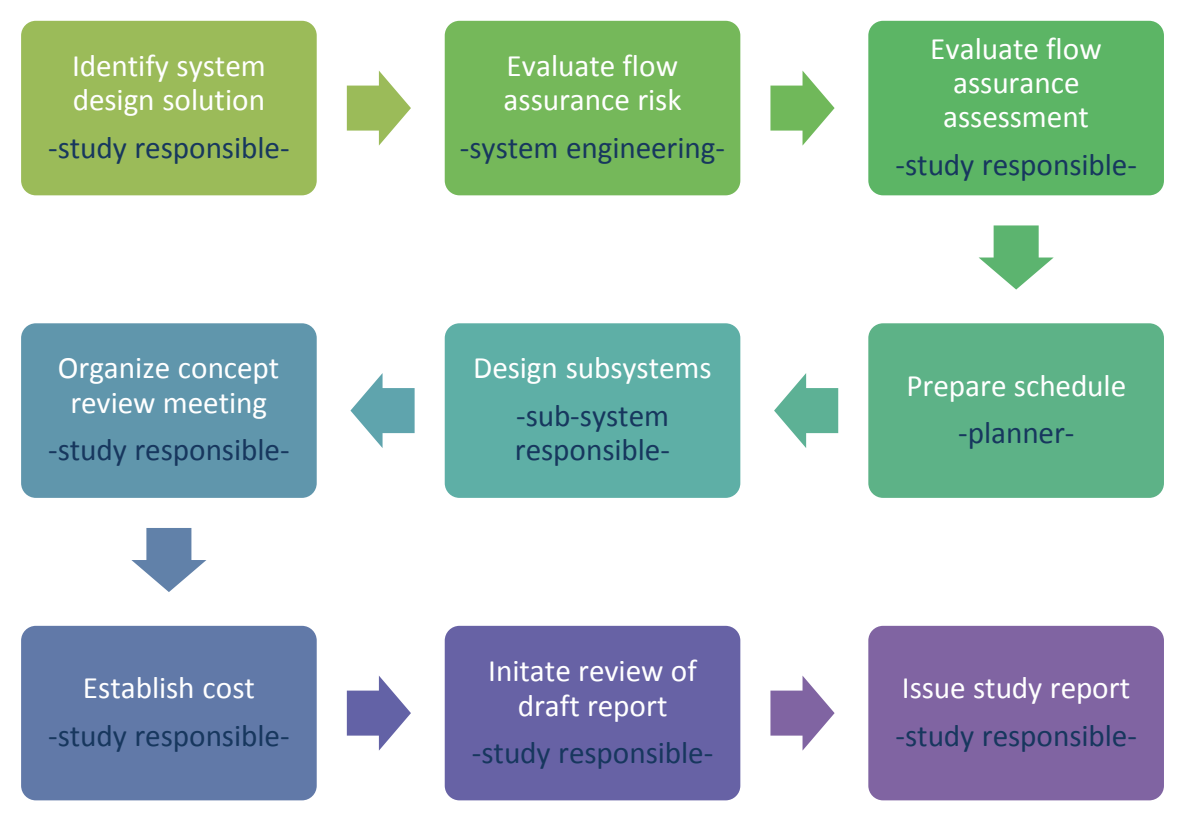

Figure 6: Execute Study
The studies are under time and cost pressure, with the consequence that the first feasible solution proposed is often selected, and the other concepts are dropped completely. The use of concept selection methods are often perceived as time consuming and are ignored in the belief that this will reduce the time pressure as detail work can start sooner.

A concept screening matrix was included in the business management system in 2012, and is defined as a required output, but this is not enforced by managers or most study owners. From FMC's business management system the following (Error!

Reference source not found.) is included for 'Organize concept review meeting'. The business process also states that the chosen concept solution shall be endorsed by the lead personnel. To the extent possible, the agreed solution shall not be altered unless customer requirements change which impact on the solution selected. To the researcher's knowledge, screening matrices are used rarely unless the customer specifically asks for it. A few engineers use evaluation matrices already, but only for internal purposes.
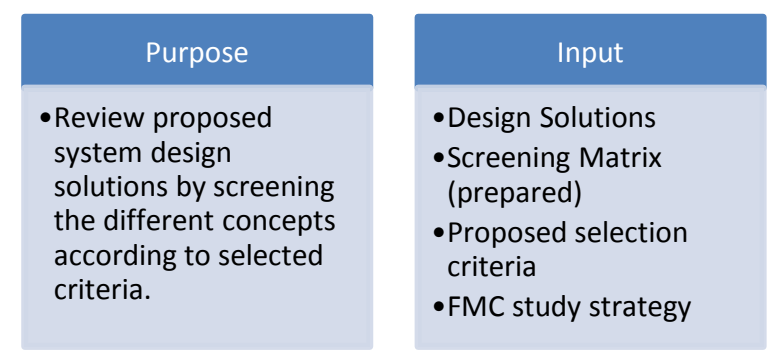

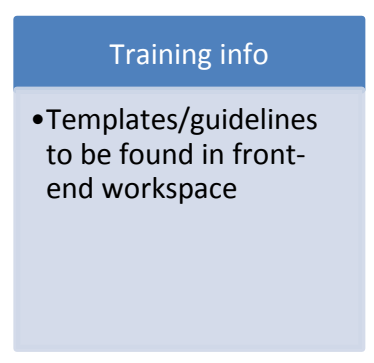

\section{Figure 7: Organize Concept Review Meeting}

\section{Presentation of System Studies}

Concept System Study A. This field is part of a current business case for a customer in Australia. A final concept select is not due for this field until 2014. This timing opens up the opportunity to investigate what

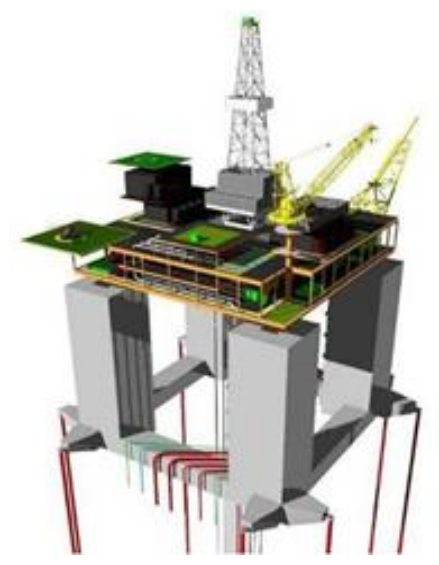

Figure 8: Dry Tree Unit technologies are currently available and may be available within the period to improve project economics/production over and above the base case. The base case is a "dry tree" unit (Figure 8) on a tension leg platform i.e. topside production system. This field has a significant number of risks: wax formation, hydrate formation, corrosive fluids (high $\mathrm{CO}_{2}$ level), long offset from shore, proximity to reef, and high sand load. The customer wants technology with high technical maturity.

The field is partly located under two adjacent coral reefs. Two of the drill centers are located in or near the channel between the reefs. There is a large tidal range in the area, which results in strong currents and high water velocities, especially in the channel. There is also a risk of sand waves near the reef. They can potentially bury parts of the subsea equipment with sand. Many tropical storms and cyclones originate or pass through the Indian Ocean in which the field is located. Sometimes, large pieces of the reef are struck off and fall into the sea. Protection of the subsea equipment shall be accounted for in the design. Tropical cyclones 
have previously disrupted oil and gas production facilities in the area. The production facilities are designed to withstand the effects of cyclones, although as a safety precaution production is usually reduced or temporarily halted and workers evacuated by helicopter to the mainland. However, dry tree units are normally not manned. The step-out from the central processing facility to the subsea processing station is $130 \mathrm{~km}$. Liquids and dry compressed gas will be exported from the central processing facility to an onshore LNG facility. The distance to shore is $310 \mathrm{~km}$. The design capacity of the subsea processing station(s) is 56.5 million standard cubic meters per day. Key requirements are wax management, hydrate management, sand handling, high technology maturity and robustness. In addition, the customer focuses on simplicity of power system and control system, low weight and size of modules to fit a standard intervention vessel for the region, and cost.

The Cases investigated are based on the cases presented and concluded on in earlier workshops with the customer (Figure 9) with exception of Option 1, which was created during the study.

Case 1A: 1 subsea processing station with inlet- and outlet temperature control, gas/liquid separation, and liquid boosting.

Case 1B: 1 subsea processing station with inlet- and outlet temperature control, gas/liquid separation, gas compression, and liquid boosting.

Case 1C: 1 subsea processing station that is based on slurry transport of stabilized hydrate and wax (cold flow) together with dry gas in 1 station.

Option 1: This case consists of 1 station with two stages of gas/liquid separation, intermediate cooling, and liquid boosting.

Case 3A: 3 stations with inlet- and outlet temperature control, gas/liquid separation, and common liquid boosting.

Case 4A: 1 station with inlet- and outlet temperature control, gas/liquid separation, free water knock out (water removal) and liquid boosting.

Case 4B: 1 station with inlet- and outlet temperature control, gas/liquid separation, free water knock out (water removal), gas compression, and liquid boosting. 


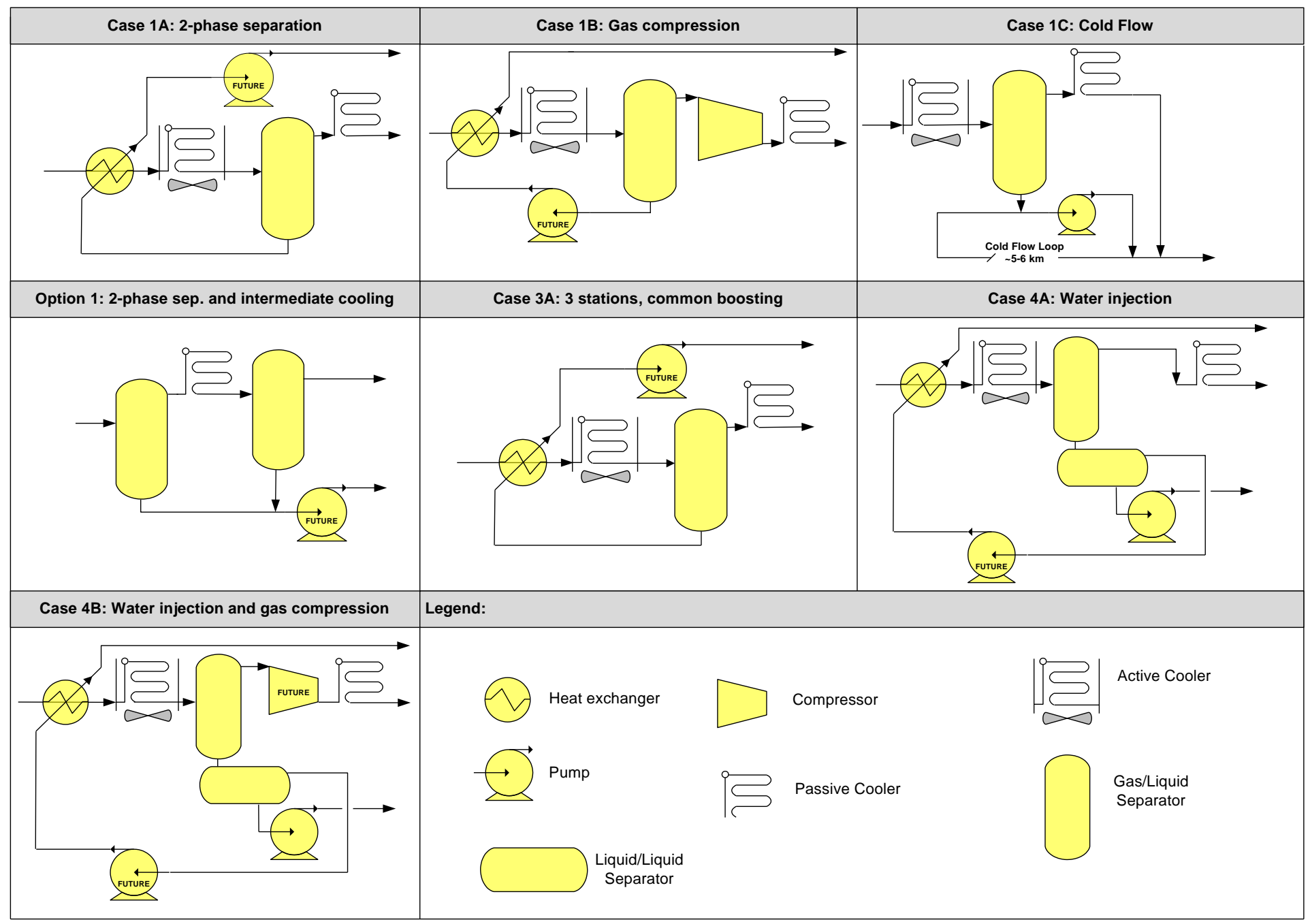

Figure 9: Study A - Design Alternatives

Concept System Study B. The concerned offshore facilities are located in the Barents Sea some $140 \mathrm{~km}$ northwest of the Norwegian coast. Water depth in the area varies between $250-350$ meters. The existing project exploits the gas resources from the fields for the production of LNG. The field development is based on subsea production with transport of the wellstream via a multiphase pipeline to an onshore LNG plant. The future development project comprises a further development of the existing facilities and the base case development includes a new LNG train onshore, additional subsea infrastructure, two subsea compression stations and potential tie-in of surrounding fields. The overall plan includes an accelerated development of the fields and increased recovery at the main field, combined with tie-in of proven gas resources within the surrounding area. The two subsea compression stations shall compress the wellstreams to enable transportation of the gas to the onshore LNG plant while meeting the inlet pressure requirements. The target is to introduce subsea compression in 2020 at the main field and 2023 at the surrounding fields. The concept is sized for a wellstream rate of 20.8 million standard cubic meters per day to coincide with the capacity of the onshore LNG plant. Key requirements are high technology maturity, robustness, simplicity of power system and control system, and weight and size of modules to fit a standard intervention vessel.

The cases to be developed and screened were decided together with the customer (Figure 10).

Reference case: This case is based on known technology from Statoil's Åsgard Subsea Compression project and Shell's Ormen Lange Pilot project.

(The Åsgard project is an ongoing EPC project for subsea compression performed for Statoil by Aker Solutions. The Åsgard subsea compression station is the world's first and will be installed in 2015. The Ormen Lange Pilot is a full scale subsea compression train designed and built by Aker Solutions that has been operated submerged in a test pit.)

Improved reference case: This case will utilize technology beyond the technology used in the Åsgard and Ormen Lange projects. 
Wet gas compression: This case will utilize a liquid tolerant/wet gas compressor. A centrifugal type compressor with the same limitations as the dry gas compressor is assumed as a reference case. No pump is needed.

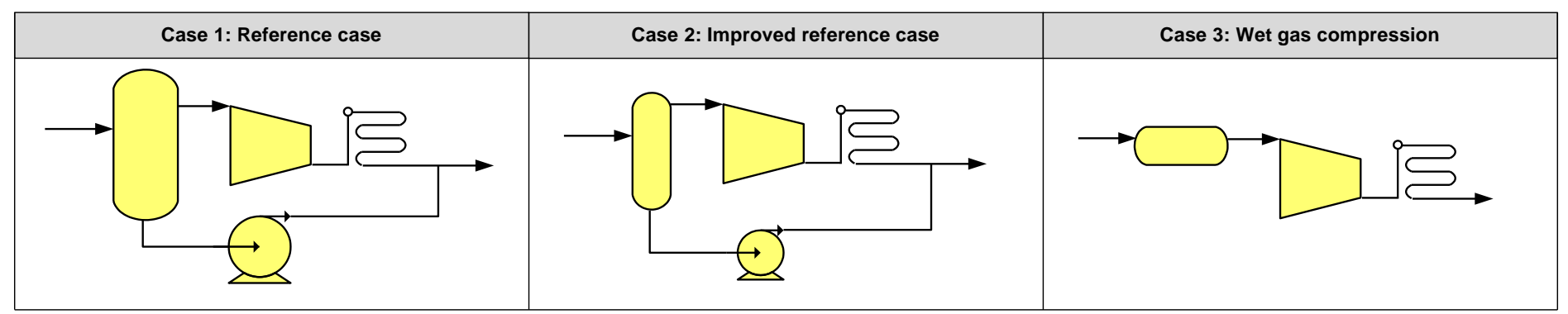

Figure 10: Study B - Design Alternatives

Concept System Study C. Design data were taken from Angolan Deep Offshore and generalized so the study was performed for a generic field application. The field is located approximately $350 \mathrm{~km}$ offshore Luanda and $130 \mathrm{~km}$ offshore Soyo. There will be free flow of gas to a topside facility, while oil, water, and sand will be boosted in a separate flowline. The liquid flowline will be insulated. The water depth is $1190 \mathrm{~m}$. Hydrate formation is expected in shut down and restart conditions. The wax appearance temperature is $32{ }^{\circ} \mathrm{C}$.

Key requirements are high technology maturity, low qualification effort, robustness, simplicity of control and operation, and weight and size of modules to fit a standard intervention vessel.

The cases to be screened were decided together with the customer based on a FMC pre-screening exercise (Figure 11).

Case 1: This case is based on known technology from the Pazflor project.

Case 2: This case will utilize technology from Pazflor, adding intermediate cooling to improve gas quality.

Case 3: This case is based on known technology from the Tordis project.

Case 4: The multipipe separator is simple and robust, but unproven. The multipipe can potentially save weight.

Case 5: Inline separation equipment minimizes space and weight and is topside proven technology. Inline separation equipment is also characterized by narrow operating envelopes.

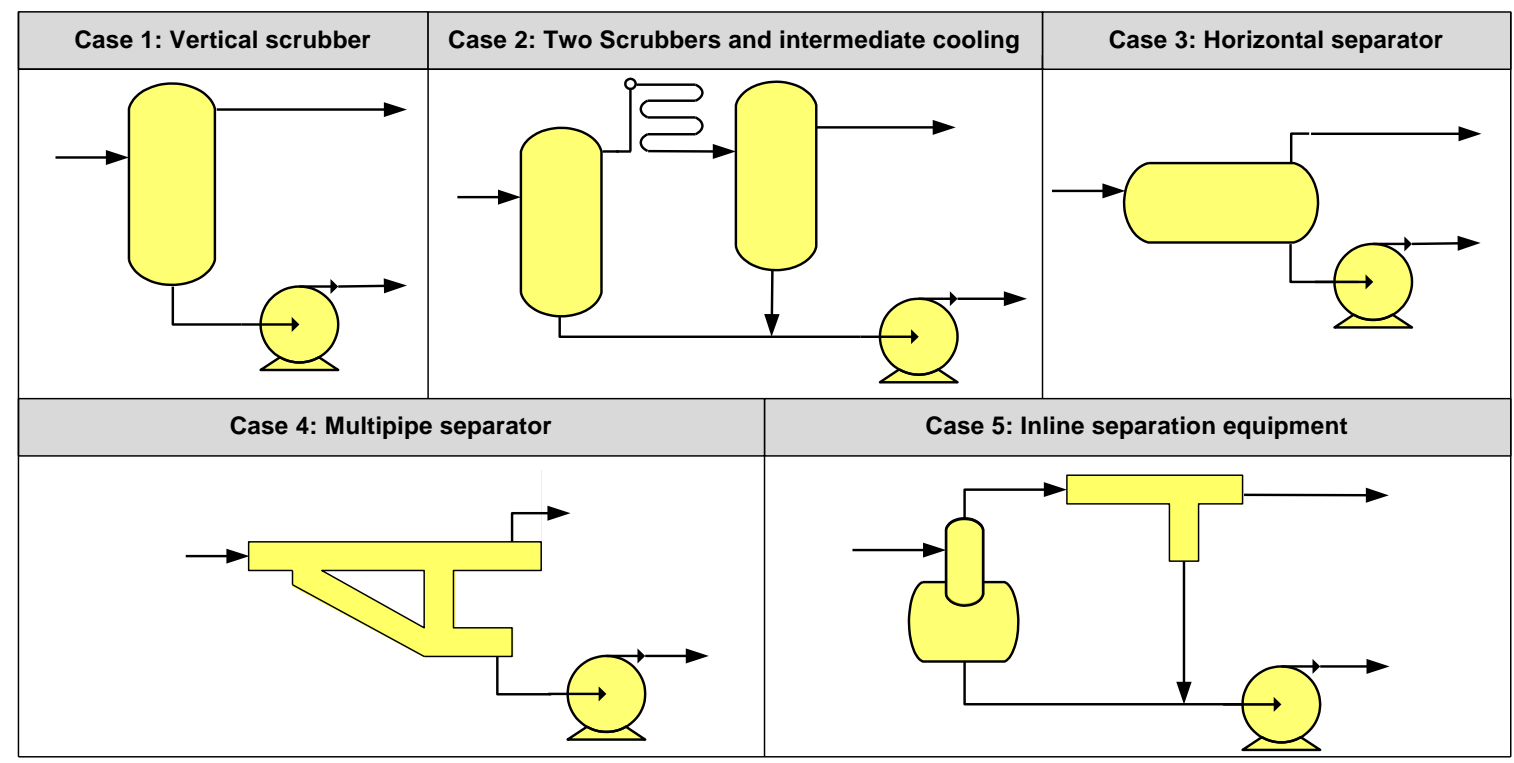

Figure 11: Study C - Design Alternatives

\section{Study Matrices - Observations, Evaluations and Learning (Action Research)}

\section{First Iteration/Cycle (Study A)}

Action Planning: The customer requested that the subsea solution should include separation and boosting of the fluids. A pre-screening exercise resulted in six cases. The FMC study team decided to use an evaluation matrix based on Pugh's with some adaption (Figure 12). The team used Excel to set up the matrix. The customer was active in selecting the cases and identifying the selection criteria. The priority scoring and weighing shown in the matrix (Figure 12) was done by the customer. 


\begin{tabular}{|c|c|c|c|c|c|c|c|c|c|c|}
\hline \multicolumn{2}{|r|}{ Criteria/Challenges } & Priority & Weight & $\begin{array}{c}\text { Case } \\
1 \mathrm{~A}\end{array}$ & $\begin{array}{c}\text { Case } \\
\text { 1B }\end{array}$ & $\begin{array}{c}\text { Case } \\
1 \mathrm{C}\end{array}$ & $\begin{array}{c}\text { Case } \\
3 \mathbf{A}\end{array}$ & $\begin{array}{c}\text { Case } \\
4 \mathrm{~A}\end{array}$ & $\begin{array}{c}\text { Case } \\
\text { 4B }\end{array}$ & $\begin{array}{c}\text { Option } \\
1 \\
\end{array}$ \\
\hline \multirow{3}{*}{ பั } & SPS CAPEX & \multirow{3}{*}{3} & 5 & 4 & 2 & 2 & 1 & 2 & 1 & 5 \\
\hline & SPS OPEX & & 3 & 4 & 2 & 4 & 3 & 2 & 1 & 4 \\
\hline & & & SUM & 9.6 & 4.8 & 6.6 & 4.2 & 4.8 & 2.4 & 11.1 \\
\hline \multirow{5}{*}{ 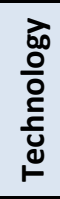 } & Maturity & \multirow{5}{*}{4} & 5 & 4 & 2 & 1 & 4 & 3 & 2 & 5 \\
\hline & TQP duration & & 3 & 4 & 2 & 1 & 4 & 3 & 2 & 5 \\
\hline & System complexity & & 4 & 4 & 2 & 3 & 4 & 2 & 1 & 5 \\
\hline & Technical safety & & 2 & 4 & 3 & 1 & 4 & 3 & 2 & 5 \\
\hline & & & SUM & 11.2 & 6.0 & 4.4 & 11.2 & 7.6 & 4.8 & 14.0 \\
\hline \multirow{9}{*}{ 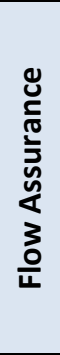 } & Wax & \multirow{9}{*}{4} & 5 & 3 & 3 & 4 & 1 & 2 & 2 & 5 \\
\hline & Hydrates & & 5 & 3 & 1 & 5 & 4 & 2 & 1 & 3 \\
\hline & Corrosion & & 5 & 4 & 3 & 3 & 5 & 4 & 3 & 5 \\
\hline & Sand & & 1 & 4 & 4 & 3 & 2 & 1 & 1 & 5 \\
\hline & Turn-down & & 3 & 3 & 4 & 4 & 2 & 3 & 4 & 5 \\
\hline & Start-up & & 4 & 3 & 3 & 1 & 5 & 2 & 2 & 4 \\
\hline & Shut-down & & 4 & 4 & 2 & 5 & 4 & 3 & 2 & 4 \\
\hline & MEG-injection & & 2 & 4 & 2 & 5 & & & & \\
\hline & & & SUM & 9.9 & 7.5 & 10.9 & 10.2 & 7.6 & 6.3 & 12.5 \\
\hline \multirow{6}{*}{$\begin{array}{l}\text { 음 } \\
\frac{0}{00} \\
\frac{0}{0}\end{array}$} & Production capacity & \multirow{6}{*}{3} & 5 & 2 & 3 & 1 & 5 & 3 & 4 & 2 \\
\hline & Personnel requirement & & 2 & 4 & 2 & 3 & 3 & 3 & 1 & 5 \\
\hline & Flexibility for future tie-ins & & 3 & 2 & 3 & 1 & 5 & 3 & 4 & 2 \\
\hline & Phased development & & 4 & 3 & 5 & 1 & 4 & 3 & 5 & 3 \\
\hline & Intervention (lift capacity) & & 5 & 5 & 2 & 1 & 5 & 3 & 2 & 4 \\
\hline & & & SUM & 7.3 & 7.0 & 2.8 & 10.4 & 6.8 & 7.7 & 7.0 \\
\hline \multirow{7}{*}{ مَ } & Reef & \multirow{7}{*}{1} & 5 & 3 & 3 & 3 & 1 & 3 & 3 & 3 \\
\hline & Distributed wells & & 5 & 3 & 3 & 3 & 4 & 3 & 3 & 3 \\
\hline & Weather conditions & & 1 & 4 & 4 & 4 & 4 & 4 & 4 & 4 \\
\hline & Sea currents & & 1 & 4 & 4 & 4 & 4 & 4 & 4 & 4 \\
\hline & Sand waves & & 5 & 3 & 3 & 3 & 1 & 3 & 3 & 2 \\
\hline & Coral breakage & & 5 & 3 & 3 & 3 & 2 & 3 & 3 & 3 \\
\hline & & & SUM & 2.3 & 2.3 & 2.3 & 1.6 & 2.3 & 2.3 & 2.1 \\
\hline & \multicolumn{3}{|l|}{ Weighted Average: } & 40 & 28 & 27 & 38 & 29 & 23 & 47 \\
\hline
\end{tabular}

Figure 12: Study A - Evaluation Matrix

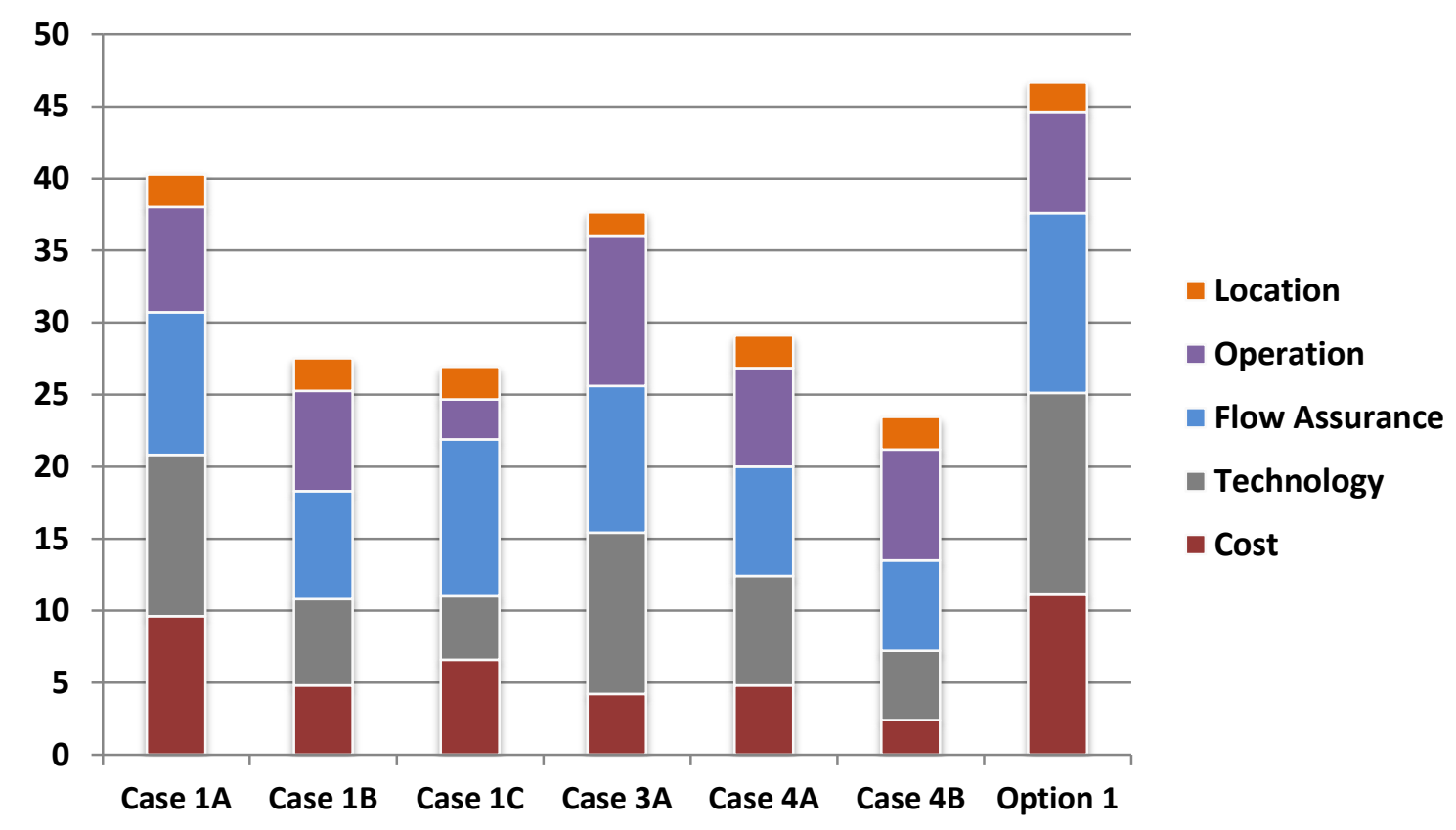

Figure 13: Study A - Bar Chart

The FMC study team scored the criteria for each design alternative. All weighting and scoring was done on a 1 to 5 Likert Scale [9], where 5 is best. The scores were defined generically by the expert team members, as the goal was to rank the different alternatives. The sums shown in the matrix for each category is calculated from 
the following formula:

Category Sum $=\frac{\sum(\text { criteria score } * \text { weight })}{\text { no of critera within the category }} * \frac{\text { Priority }}{\text { no of categories }}(1)$

The bar chart was added to the matrix at the end of the screening process and is based on the category sums for each design alternative. The weighted average (overall sum) is shown in the bottom row of the matrix.

Observations \& Evaluations: The team was confused by toggling between all the different screen views; matrix, supporting notes, and case sketches. This disturbed the concept selection somewhat. The bar chart (Figure 13) presented a good overview, but it was difficult to see small differences in bar chart. Option 1 was discovered during the process as indicated as a benefit by Pugh [1]. Option 1 ended up being the selected concept. The application of the Pugh matrix in this case allowed more alternatives than is normal practice.

The customer was highly involved during the execution of this study. As the conceptual design matured, the customer involvement resulted in scope creep. They also changed some of the basic design parameters during the study and caused a lot of re-work to be done. Despite a stressed team, the main personnel, who were $100 \%$ allocated to this study, did the additional work in a short intense period. The upside to customer involvement in populating the matrix is quality assurance of selected parameters and weighting of the criteria.

When the matrix was set up with parameters, priority, and weighting, the study team assigned the individual scores. This was the first time several of the team members saw an evaluation matrix and there was some initial confusion. When this was resolved, the team seemed pleased; populating the matrix went very well and it served its purpose. One additional case, option 1, was discovered as a result of populating the matrix and scoring. This was mainly due to a greater understanding of the design problem. If this had not been discovered so early, a substantial amount of re-work would have to be performed late in this study, or the option not discovered at all. The observations were confirmed in post-interviews with two of the team members.

Specifying Learning (input to next cycle): The number of toggles between different screen views used during the concept review meeting must be reduced. Sketches of the concepts and a placeholder for notes should be added to the matrix. The bar chart visualizes the differences between the cases and the contributions from each main category. The chart reduces the amount of information and helps to focus on the differences. The team also found the bar chart useful for communicating the results to others (presentations and reports). The bar chart should include data labels to visualize small differences. An explanation of the matrix set-up should be made prior to assigning weights and scores. The matrix can be improved by using more colors.

\section{Second and Third Iterations/Cycles (Study B and Study C)}

Action Planning: The format of the matrix from study B and C are almost identical. Figure 14 and Figure 15 are taken from the matrix used in study C. The FMC study teams used an evaluation matrix based on the one used in study A with the improvements from the first cycle incorporated. The matrices were set up using Excel. The evaluation criteria were grouped into main categories that were assigned an overall priority. Within each category the individual evaluation criteria were weighted related to the others in that category and given a score between 1 and 6 based on compliance to requirements:

1 - not compliant

2 - major compliance gap

4 - minor compliance gap

5 - insignificant compliance gap

3 - compliance gap

6 - fully compliant

The study teams and the customer (study C) preferred that all the weights and priorities were in percentage as they thought it was easier to relate to, and would improve the quality of the process. The project team established the following guide for the criteria:

$0-5 \%$ : unimportant

50-75\%: very important

5-25\%: slightly important

75-100\%: critical
25-50\%: important

(The sum of weights and priority shall be exactly 100\%). 


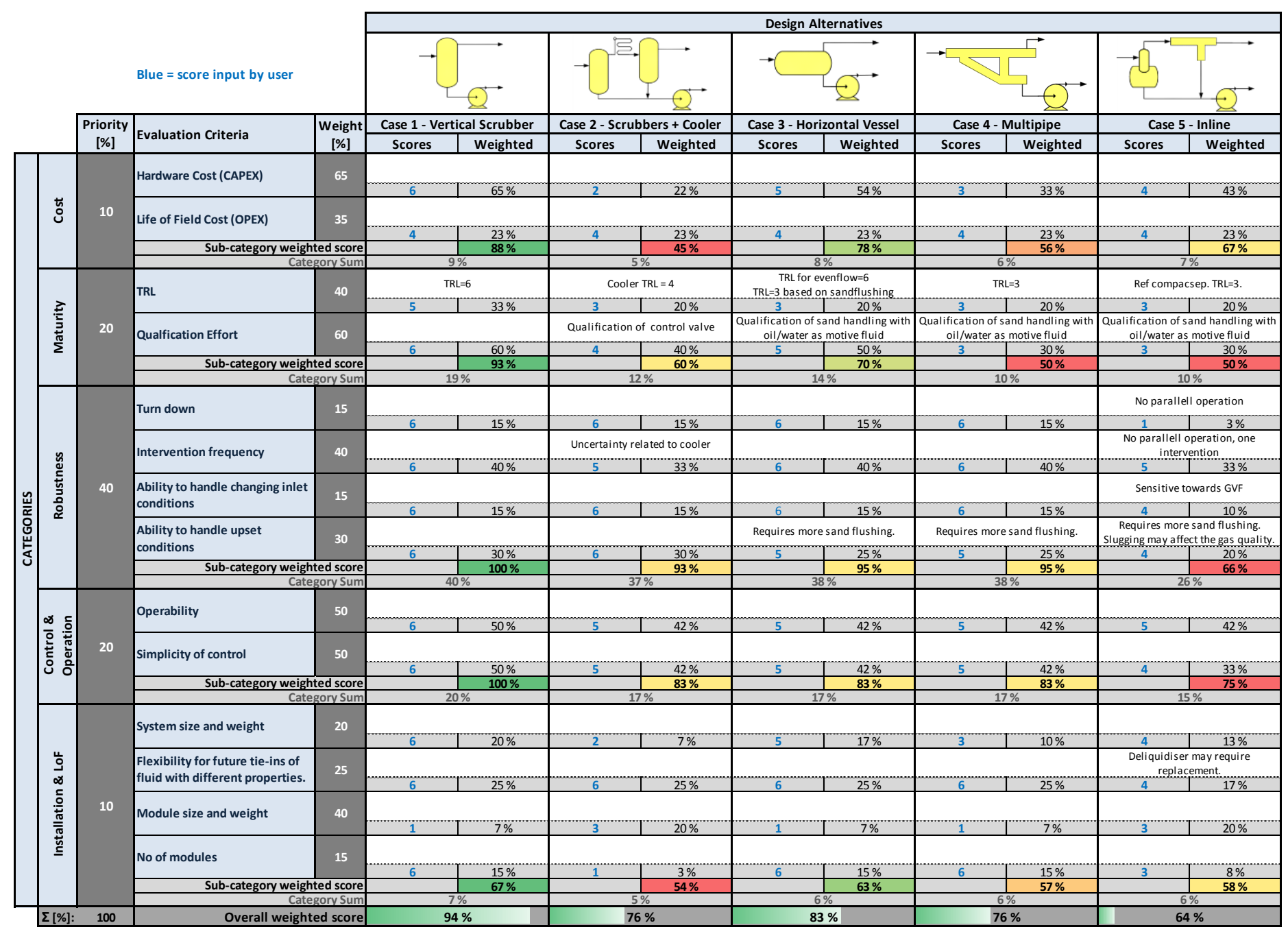

Figure 14: Study C - Evaluation Matrix

The following formulas are used in the matrix above:

Criteria weighted score $=\frac{\text { Criteria Score }}{6(\max \text { score })} *$ weight $[\%](2)$

Subcategory weighted score $=$ ECriteria weighted scores [\%] (3)

Category Sum $=\frac{\text { Subcategory weighted scores }[\%]}{100} *$ Priority $[\%](4)$

Cost Category Example:

$$
\text { Cost Category Sum }=\frac{\left(\frac{6}{6} * 65+\frac{4}{6} * 35\right)}{100} * 10 \%=\underline{9 \%}
$$

The bar chart below is based on the category sums for each design alternative. The overall weighted score (total score in the bottom row) is the sum of the category sums (equation 4). The overall weighted score is also shown in percentage. A total score of $100 \%$ is the maximum achievable. 


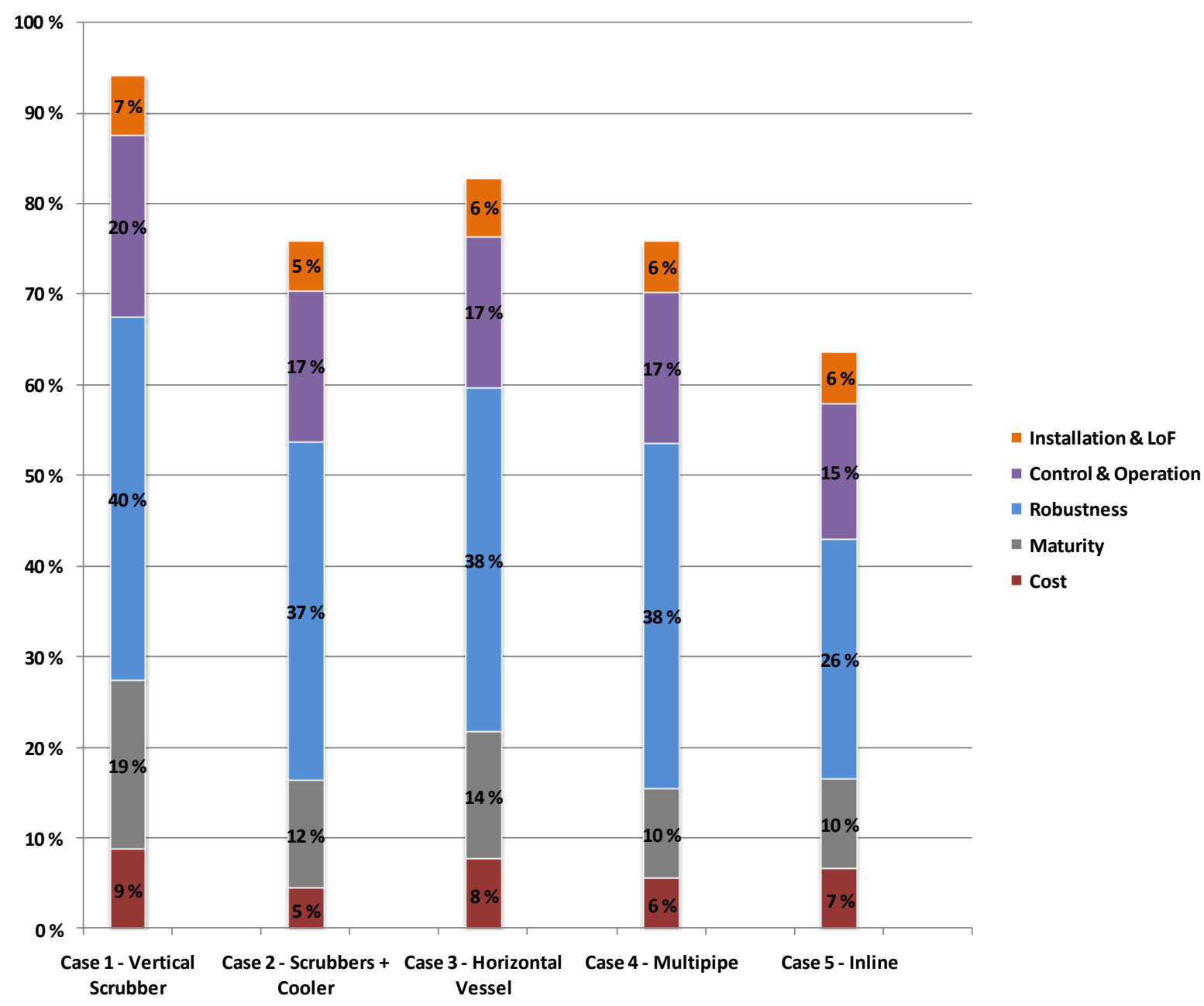

Figure 15: Study C - Bar Chart

Observations \& Evaluations from Study B: The screening in study B was used by the project team to rank the three concepts. The customer wanted all three of them further investigated, where FMC should make a recommendation. The matrix was used to establish this ranking of concepts as an internal exercise.

In study B, the customer did not ask for a matrix. The team appreciated the matrix as the three concepts were similar, but complex and the matrix helped the team to structure and align prior to building the report and final presentation. The customer wanted weekly meetings. FMC presented the status and technical solution in these meetings. This study was executed by engineers from another study team, because of the similarities. Due to scope creep and full time allocation to the other study, this study was perceived as very stressing and time constrained. During post-interviews the team reported their appreciation for the matrix structural process and the documenting process for the rationale behind the selections made. This was especially important with resources jumping in and out of this study. Due to the similarities with the other study, the team members often mixed up the cases and reasoning. The matrix was edited during the meetings if overlapping or new criteria were found. The team seemed to appreciate the immediate visual response in the evaluation matrix and bar chart.

Specifying Learning from Study B (input to next cycle): The bar chart should be used more for clarifying while the matrix is being populated. The layout should stay the same.

Observations \& Evaluations from Study C: The screening in study C was used together with the customer. The matrix was a good visual communication tool. The customer wanted case 2 included. If this was an internal exercise, this alternative would not have been considered. This study was characterized with relatively low intensity. The team set up and populated the evaluation matrix without stress. The engineers in this team were young and highly educated, some of them new to FMC. The understanding of the matrix was never a problem. The atmosphere in these meetings was very pleasant. The customer wanted the spreadsheet for internal use.

The participants used the matrix and the bar chart in conjunction to allow a shift of focus from detail level (Figure 14) to high level (Figure 15). 


\section{Analysis and Validation of Pugh Matrices}

The engineers in the study teams filled in a questionnaire to evaluate the application of the Pugh matrix. The statements in the questionnaire were ranked using a pre-defined Likert scale (Figure 16). Likert scales have a rank order, but the intervals between values cannot be presumed equal [9]. The numbers represent verbal statements, and the results are not presented by means of mathematical analysis.

Legend:

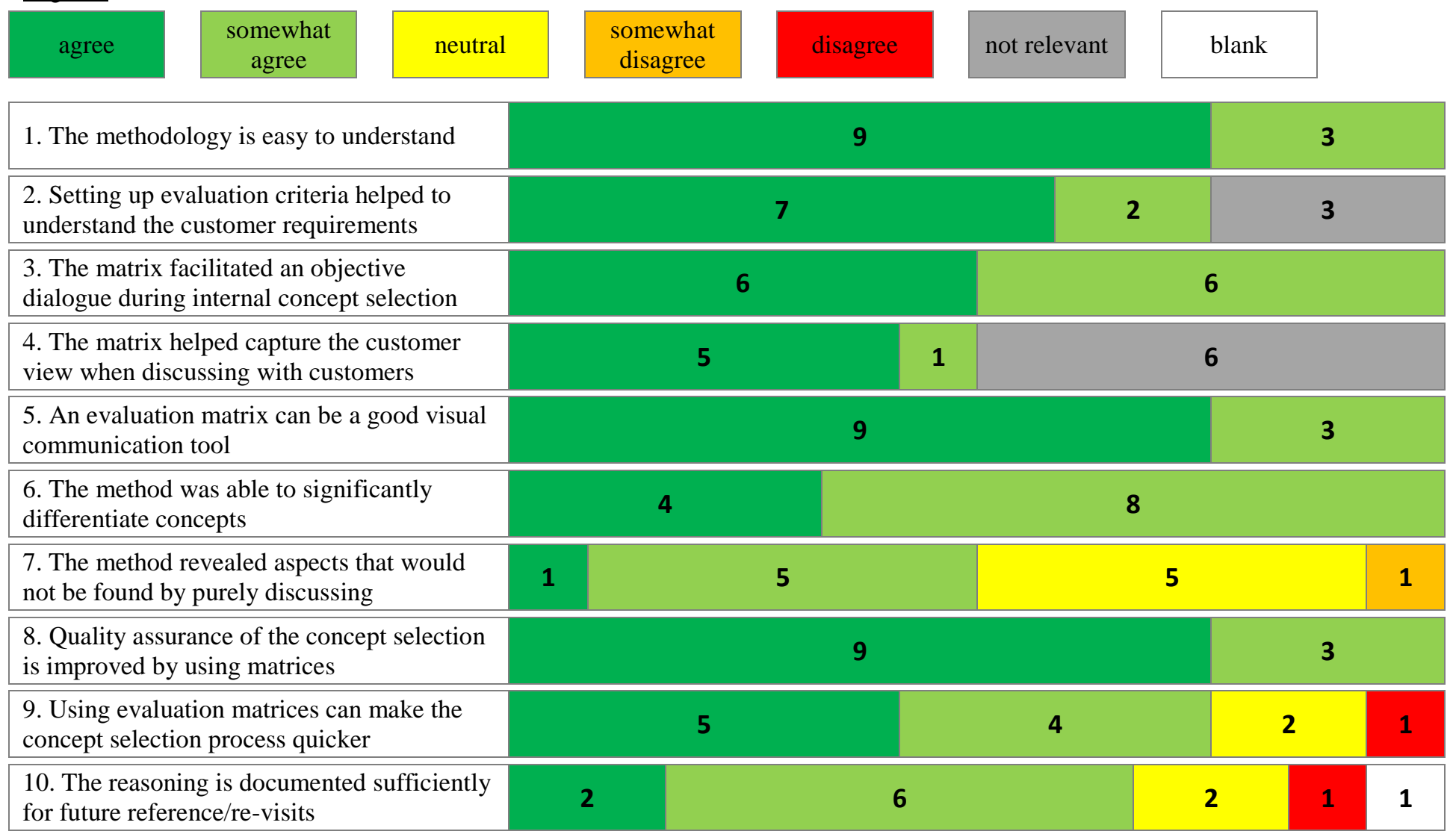

Figure 16: Questionnaire Results - Part 1

The questionnaire also contained yes and no questions. Readers must take care when interpreting yes/no type feed-back, only trends are used for conclusion (Figure 17).

Legend:

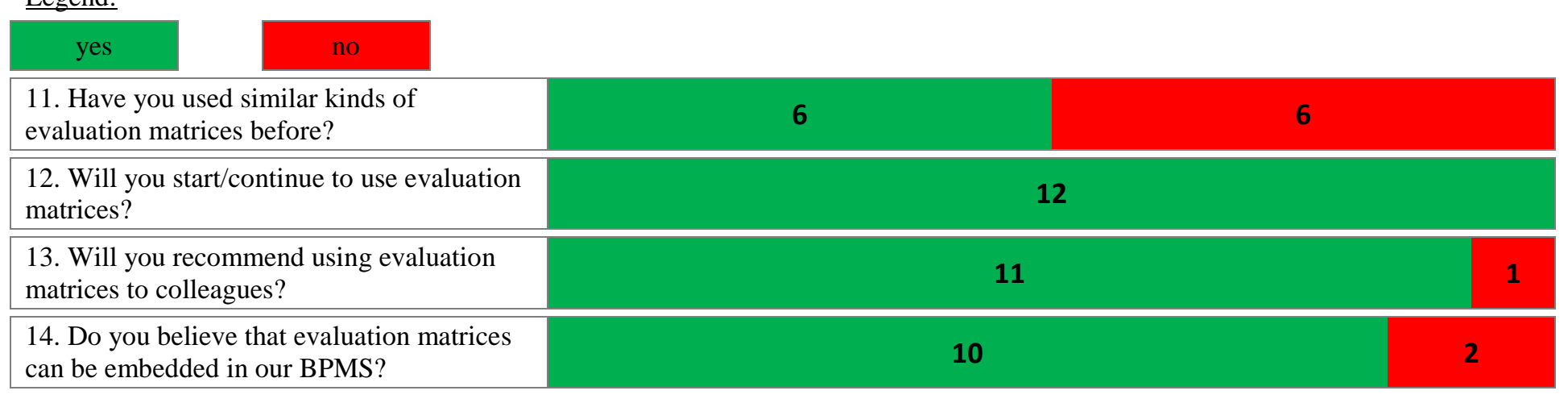

BPMS - Business Process Management System

Figure 17: Questionnaire Results - Part 2

The results from the questionnaire are very positive. This was also confirmed in the post-interviews. Half of the participants had used evaluation matrices before. This is a high number, but not unlikely as there are a few engineers in the subsea process systems department that sometimes use evaluation matrices. The participants found the Pugh matrix easy to use and will continue to use it. They also support that concepts are significantly differentiated and that quality assurance is improved by using evaluation matrices. The study teams achieved a greater understanding of the design problem by using the matrix in the concept selection process. This was confirmed during observations and post-interviews. 
During action research/industry-as- laboratory, the researcher focused on turning the people involved into researchers too. People learn best, and more willingly apply what they have learned, when they do it themselves [4]. The feedback from the teams is more positive than the previous papers presented by FMC master students $[10,0]$. This may be influenced by an increasing attention from the customers to have insight into the reasoning behind the screening.

\section{Discussion}

Concept selections in the subsea processing domain often concern a high number of interrelated criteria. The human mind struggles to handle the complexity and interrelation of these large data sets of criteria. This may result in inconsistent and incorrect decisions.

Pugh claims that matrices in general are the best way of structuring and representing an evaluation, as they give structure and control to the concept selection process. The authors of the previous FMC master papers $[5,6,8]$ also concluded that the Pugh matrix is a suitable format for the subsea domain. However, the participants in the previous research papers were reluctant to use the matrix in concept selections $[5,6,7,8]$. On the contrary, this research shows that the Pugh matrix was appreciated amongst the engineers. All the participants wanted to continue to use evaluation matrices, and nearly all will recommend them to other colleagues. One reason for this positive attitude may be that the technical solutions and field challenges in the subsea processing studies are increasingly complex and a structural approach seems to be appreciated, also among experienced engineers. Further, the engineers realize that selecting the right concept early is important to secure a successful result, and this may make them appreciative of the process used for concept selection and susceptible to use evaluation matrices in the future. People need assurance that they have selected the right concept. Gut feeling is not to be underestimated, but in today's working environment it needs to be substantiated with rationales to be perceived as credible.

An additional explanation can be that customers more often want to see the reasoning behind the concept selection and this is forcing a more thorough approach, as it is difficult to build a good report if the evaluations have not been performed.

Another contributing factor may be that this research was performed amongst young engineers; only 2 of the 13 engineers were above 40 years of age. In addition, FMC's global and regional managers have recently increased the focus on quality and launched several campaigns to improve quality. The campaigns aim at changing people's mindset and behaviors towards clear requirements, avoid workarounds, and develop, implement, and maintain zero-defect capable processes. These campaigns have been launched after the papers referenced $[5,6,8]$ were written and might have helped in achieving a more open attitude towards concept selection processes and tools.

Concept selection matrices are part of the company process, and apparently, more work is required to have the engineers use it as the default approach for concept selections, as they are currently seldom used. One of the major hindrances is that there currently is no enforcement from managers to use evaluation matrices, despite its prescription in the business process management system. The matrix presented in this paper can be implemented as a decision making tool for the subsea process systems department. This will improve quality assurance during concept selections. Incorrect selection criteria will obviously lead to the wrong decision. It is important to put the required time and effort into determining the criteria and validate these with the customer, as done in the studies of this research. However, management attention and follow-up is required.

Customer involvement is undoubtedly necessary to be able to select the correct screening criteria. One concern is that when having full visibility of the matrix towards the customer, it limits the possibility for FMC to influence the results strategically. It was also noticed that when the matrix were to be submitted to the customer, the engineers were reluctant to use the lower part of the scoring values. They were afraid that the customers could misuse low rated equipment in other contexts where the equipment would meet the requirements. 


\section{Conclusions}

It is claimed that evaluation matrices in general are a good way of structuring and representing an evaluation, as they add structure and control to the concept selection process. The research performed in the three subsea processing studies confirms this statement. The positive feedback from the engineers concludes that an evaluation matrix

- helps to understand the customer requirements

- are a good visual communication tool

- facilitates an objective dialogue

- improves quality assurance of the concept selection

The suggested layout of the matrix and screening process presented in this paper can be implemented as a decision making tool for the subsea processing department to enable quality assurance during concept selections. For the method to be applied successfully, time must be made available to perform the proper evaluations. In addition, better training and understanding of the benefits of evaluation is needed. Customer involvement and management focus and follow up are required.

\section{Future Research}

It is recommended to perform concept selections using Pugh Matrices in studies and projects that have larger teams and scope than those presented in this paper - also for studies within other areas involving more mature technology. This paper included projects from early system studies.

Evaluation matrices need to be researched in other project phases and in sub-system design. The researcher can then conclude on a broader basis if Pugh matrices are successful - the limitations and potential pitfalls of the method should also be subject to further research.

The involved engineers in this research were relatively young. Previous papers state that older and experienced engineers are reluctant to apply the Pugh matrix. To further investigate if the observed change in the attitude is valid for the entire subsea processing department, a larger variety of team members must be included in the research.

\section{References}

[1] Stuart Pugh, Total Design - Integrated Methods for Successful Product Engineering, ISBN 0-201-41639-5, 1991.

[2] Gerrit Muller and W. P. Maurice Heemels, Five Years of Multi-Disciplinary Academic and Industrial Research: Lessons Learned, CSER 2007 in Hoboken NJ.

[3] Colin Potts. Software-engineering research revisited. IEEE Software, Vol. 10, No. 5:19-28, September/October 1993.

[4] O'Brien, R, An Overview of the Methodological Approach of Action Research. University of Toronto http://www.web.ca/robrien/papers/arfinal.html\#_edn2, 1998.

[5] Dag Jostein Klever, Needs and concept analysis, a case study for subsea connections, Master Project Paper, Buskerud University College, 2009.

[6] Halvard H. Bjørnsen, Concept Development Case Study; Swivel Element for an Optimized Flowline Spool, Master Project Paper, Buskerud University College, 2009.

[7] Gerrit Muller, Concept Selection; Theory and Practice, Buskerud University College, White paper of SESG meeting November 6, 2009.

[8] Vebjørn Nedrestøl, An engineering study regarding further developing of a Riser Telescopic Joint, Master Project Paper, Buskerud University College, 2010.

[9] Jamieson, Susan, Likert scales: how to (ab)use them. Medical Education. http://xa.yimg.com/kq/groups/18751725/128169439/name/1LikertScales.pdf, 2004.

[10] Gerrit Muller, Dag Jostein Klever, Halvard H. Bjørnsen, and Michael Pennotti, Researching the application of Pugh Matrix in the sub-sea equipment industry, CSER 2011 in Los Angeles. 